\title{
Nonlinearity in the North Pacific atmospheric response to a linear ENSO forcing
}

\section{Journal Article}

Author(s):

Jiménez Esteve, Bernat (D); Domeisen, Daniela (i)

Publication date:

2019-02-28

Permanent link:

https://doi.org/10.3929/ethz-b-000323829

Rights / license:

In Copyright - Non-Commercial Use Permitted

Originally published in:

Geophysical Research Letters 46(4), https://doi.org/10.1029/2018gl081226

Funding acknowledgement:

170523 - Improving the Prediction of Sub-seasonal to Seasonal Weather and Climate - From Theory to Application (SNF) 


\section{Geophysical Research Letters}

\author{
RESEARCH LETTER \\ 10.1029/2018GL081226 \\ Key Points: \\ - In a simplified atmospheric model, \\ linear changes in strength of \\ ENSO SST forcings yield nonlinear \\ teleconnections \\ - The ENSO teleconnection to \\ the North Pacific exhibits strong \\ nonlinearity mainly for strong $\mathrm{El}$ \\ Niño events \\ - The extratropical nonlinearity \\ is traced to the relation between \\ convection and SST in the tropical \\ Pacific
}

Supporting Information:

- Supporting Information S1

Correspondence to:

B. Jiménez-Esteve,

bernat.jimenez@env.ethz.ch

Citation:

Jiménez-Esteve, B., \&

Domeisen, D. I. V. (2019).

Nonlinearity in the North Pacific

atmospheric response to a linear

ENSO forcing. Geophysical

Research Letters, 46, 2271-2281.

https://doi.org/10.1029/2018GL081226

Received 6 NOV 2018

Accepted 30 JAN 2019

Accepted article online 5 FEB 2019

Published online 18 FEB 2019

C2019. American Geophysical Union. All Rights Reserved.

\section{Nonlinearity in the North Pacific Atmospheric Response to a Linear ENSO Forcing}

\author{
B. Jiménez-Esteve ${ }^{1}$ (D) and D. I. V. Domeisen ${ }^{1}$ (D) \\ ${ }^{1}$ Institute for Atmospheric and Climate Science, ETH Zurich, Zurich, Switzerland
}

\begin{abstract}
El Niño Southern Oscillation (ENSO) exerts a remote impact on the North Pacific and North American winter climate. Both observational and model studies have suggested nonlinearities in this teleconnection. However, it remains unclear if possible nonlinearities arise from the forcing strength or the forcing location in the tropical Pacific, or from factors external to the tropical Pacific. To separate these factors, an idealized model is forced with seasonally varying sea surface temperature with linearly varying strength at a fixed location. Whereas for moderate events the North Pacific response is more linear, strong events exhibit significant nonlinearity both in terms of the strength and location of the impact. The nonlinearity can be traced back to the relationship between sea surface temperature and tropical convection. Nonlinearity in the North Pacific response can have important impacts for long-range prediction and for potential changes in the diversity of ENSO with climate change.
\end{abstract}

Plain Language Summary El Niño Southern Oscillation (ENSO) is an atmosphere-ocean coupled phenomenon in the tropical Pacific. Sea surface temperatures (SST) oscillate between a warm phase (El Niño) and a cold phase (La Niña). Anomalous SSTs are linked to changes in tropical rainfall, leading to a global influence. One of the most prominent influences takes place during Northern Hemisphere winter in the North Pacific and North America. However, each ENSO event is intrinsically different, and so are its impacts. Differences in the impacts can arise from differences in the exact location and strength of the SST anomalies in the tropics. To separate these factors, we use an atmospheric model and prescribe seasonally varying SSTs with linearly varying strength at a fixed location. Whereas for moderate events the impacts in the North Pacific are more linear (El Niño and La Niña have similar but opposite impacts), strong events exhibit significant nonlinearity (strong ENSO events yield more than twice the impact, especially for El Niño). The nonlinearity can be traced back to the relationship between SST and tropical rainfall. Our results have important implications for projected changes in the ENSO characteristics with climate change, which could nonlinearly impact the remote effects of ENSO.

\section{Introduction}

El Niño Southern Oscillation (ENSO) is an atmosphere-ocean coupled phenomenon that accounts for the dominant part of interannual variability in the tropical Pacific (Philander, 1990). It manifests in surface winds, pressure, and sea surface temperatures (SST) that alternate between a warm (El Niño, EN) and a cold phase (La Niña, LN). ENSO events exhibit significant diversity according to two major characteristics, which are themselves linked: the magnitude and the longitudinal location of the maximum SST anomalies (Capotondi et al., 2015; Timmermann et al., 2018), often referred to as "asymmetry" or "nonlinearity" (An, 2004; An \& Jin, 2004; Domeisen et al., 2018). The strength and longitudinal location of the maximum SST anomaly for EN exhibits more variability than for LN (Figure S3; Capotondi et al., 2015; Dommenget et al., 2013). A possible explanation for this asymmetry is the nature of atmosphere-ocean feedbacks (Bayr et al., 2018; Dommenget et al., 2013; Frauen \& Dommenget, 2010). EN events are therefore often separated into central (CP) and east Pacific (EP) events (Ashok et al., 2007), while this separation is weaker for LN (Kug \& Ham, 2011).

This asymmetry is not limited to the tropics, since ENSO exhibits a strong extratropical influence through teleconnections (see reviews by Liu \& Alexander, 2007, and Stan et al., 2017). One such teleconnection is observed during winter in the North Pacific and the North American continent (Bjerknes, 1969; Halpert \& Ropelewski, 1992; Horel \& Wallace, 1981; Mo \& Livezey, 1986; Ropelewski \& Halpert, 1987; Sardeshmukh \& Hoskins, 1988; Trenberth et al., 1998; Yu et al., 2012), providing an important source of 
predictability for North America (e.g., Infanti \& Kirtman, 2016; Ropelewski \& Halpert, 1987). The EN teleconnection consists of a strengthened Aleutian low (AL) and a southward shift and eastward extension of the tropospheric jet and the storm track (Seager et al., 2010). These anomalies are associated with a positive phase of the Pacific North American (PNA) pattern (Leathers \& Palecki, 1992; Leathers et al., 1991), which manifests as warm temperature anomalies over northwestern North America and increased precipitation over the southern United States (e.g., Jong et al., 2016). The teleconnection arises from an increase (decrease) of tropical deep convection leading to a strengthening (weakening) of the upper level divergent flow (Wang, 2004). Rossby wave trains excited by the interaction of the divergent flow with the vorticity gradient propagate poleward (Sardeshmukh \& Hoskins, 1988; Hoskins \& Karoly, 1981), where extratropical anomalies are maintained by midlatitude wave-mean flow interaction (Franzke \& Feldstein, 2005). The source of forced Rossby waves depends on the position of the tropical convection (Garfinkel et al., 2018; Taschetto et al., 2016). Opposite-signed conditions tend to be observed during LN, yet—given the asymmetry in the tropical Pacific - there are important asymmetries in the strength and location of extratropical precipitation and temperature anomalies between EN and LN (e.g., Deser et al., 2018; T. Zhang et al., 2014).

Several climate models project that strong EN events will become more frequent in a future climate (Cai et al., 2014, 2018; Latif \& Keenlyside, 2009; Timmermann et al., 1999). This could have important consequences as stronger EN events have been linked to stronger and more nonlinear teleconnections (Hoerling et al., 1997, 2001; Jong et al., 2016). While it is unresolved where the nonlinearity originates, one of the possible sources is the nonlinear convective precipitation response to surface SST anomalies (Cai et al., 2014; Chung \& Power, 2015; Hoerling et al., 2001), including the $27-28^{\circ} \mathrm{C}$ convection threshold (Chiodi \& Harrison, 2013; Frauen et al., 2014; Johnson \& Kosaka, 2016; C. Zhang, 1993). Whether these nonlinearities in the tropical Pacific are responsible for nonlinearities in the extratropical North Pacific response is not resolved (Frauen et al., 2014).

The limited availability of observations complicates the identification of nonlinear effects in the North Pacific response to ENSO (Deser et al., 2017, 2018; Domeisen et al., 2018). Garfinkel et al. (2018) found that at least 15 events of each type are required to identify statistically significant nonlinearities. The three extreme EN events (1982/1983, 1997/1998, and 2015/2016) in the observational record are therefore not sufficient to establish a possible nonlinear relationship from observations. Atmospheric models can be used to alleviate this problem, and many modeling studies using large sample sizes have indeed identified nonlinearities, for example, Frauen et al. (2014), Garfinkel et al. (2013), Hoerling and Kumar (2002), Hoerling et al. (1997, 2001), Johnson and Kosaka (2016), and T. Zhang et al. (2014). However, it remains unresolved to what extent the North Pacific nonlinear winter response to ENSO arises from ENSO strength, location, or from external atmospheric processes relevant for the teleconnections. The targeted model simulations performed in this study allow for a separation of the relative contributions to the potential nonlinearity of the extratropical response. By forcing a linear change in the amplitude of the SSTs at a fixed forcing location and by forcing climatological extratropical SST anomalies, the model experiments isolate possible nonlinearities arising solely through changes in ENSO strength.

The paper is organized as follows: A brief description of the model and the experiments is provided in section 2. Sections 3 and 4 describe the model response to the ENSO forcings, and the last section summarizes and discusses the main results.

\section{Model Description and Methods}

In this study we use Isca (Vallis et al., 2018), a framework for the idealized modeling of the global atmospheric circulation, which has been extensively used to simulate a wide range of atmospheric phenomena (Geen et al., 2018; Thomson \& Vallis, 2018a, 2018b). It uses the Geophysical Fluid Dynamics Laboratory dynamical core. We use an intermediate complexity configuration (see supporting information for more details). Moist processes are considered through evaporation from the surface and fast condensation (i.e., no explicit liquid water content in the atmosphere) which interacts with the radiation and the convection scheme. We use realistic topography and the continental outline from the ECMWF model (Dee et al., 2011). The land-sea contrast is achieved by changing surface characteristics such as the mixed layer depth, evaporation resistance, and albedo (Thomson \& Vallis, 2018a). The model uses a Gaussian grid with a resolution of T42 and 50 vertical levels up to $0.02 \mathrm{hPa}$. 

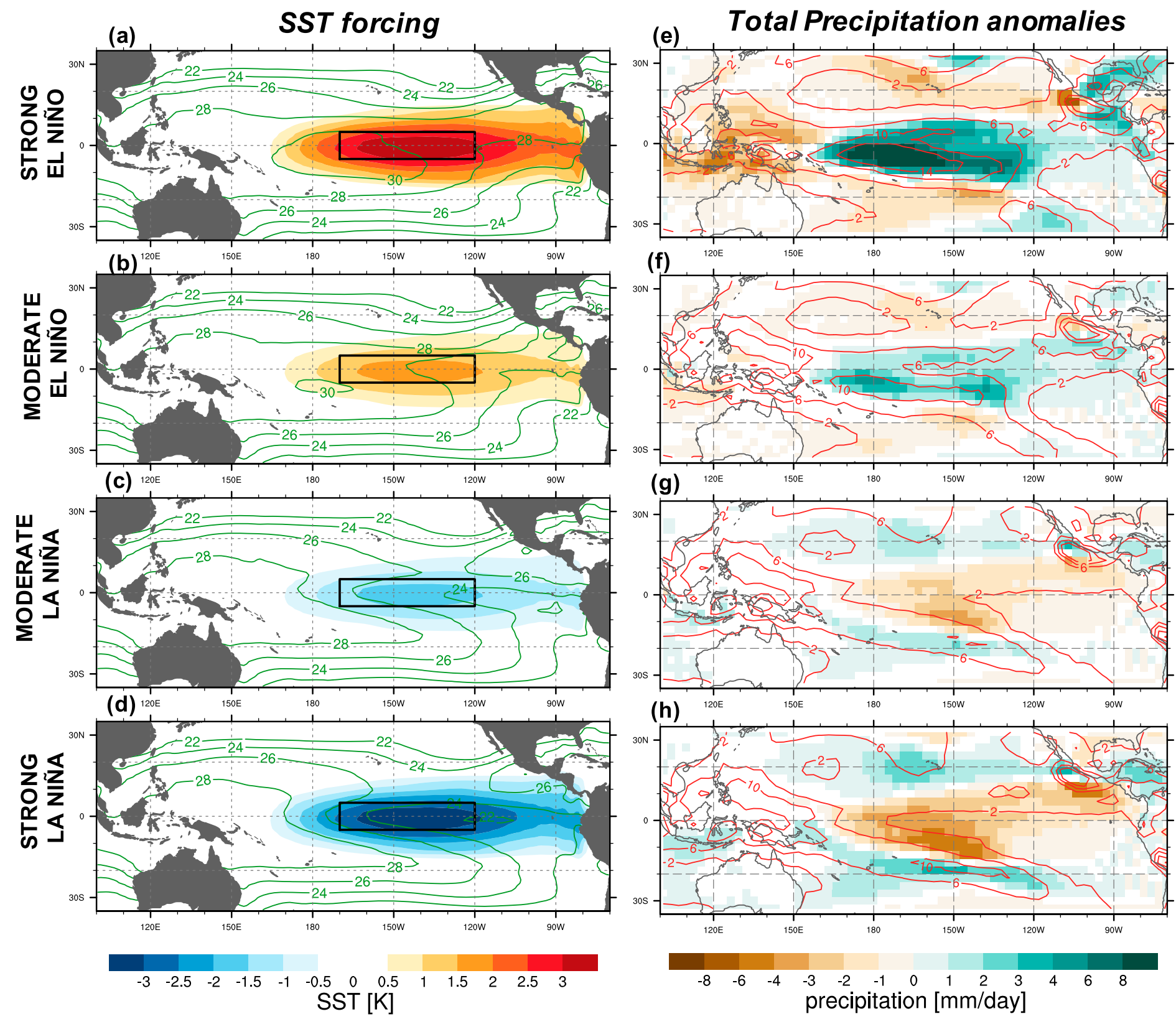

Figure 1. (a-d) December-January-February SST forcing and (e-h) December-January-February mean precipitation model response (shading: resolved + parameterized) for (a, e) strong and (b, f) moderate El Niño, and for (c, g) moderate and (d, h) strong La Niña forcing. Contour lines indicate absolute values of SST $\left({ }^{\circ} \mathrm{C}\right.$ ) and precipitation (mm/day), respectively. Black boxes in (a-d) indicate the geographical area for defining the Niño3.4 index. Only statistically significant values above the $99 \%$ confidence level are shown for precipitation. SST $=$ sea surface temperature.

The performed experiments mimic the tropical Pacific ENSO-like SST forcing. The model uses prescribed fixed SSTs following the 1958-2016 monthly SST climatology from NOAA ERSSTv4 (Huang et al., 2015; daily values are linearly interpolated). The experiments consist of a climatological run and four experiments with tropical ENSO-like forced SSTs. Forced SST anomalies are obtained by regressing the standardized October-November-December-January-February (ONDJF) mean Niño3.4 index onto the SST field for each month into the future for January to July and into the past for December to May. To generate a smooth seasonal cycle the May-July values are averaged between the regressions into the future and the past. Only positive (negative) SST anomalies are retained for the EN (LN) forcing. We use climatological SSTs north and south of $15^{\circ}$ and outside of the Pacific basin $\left[150,280^{\circ} \mathrm{E}\right]$. The obtained anomaly SST pattern is multi- 
plied by a factor of $+(-) 2$ to obtain a moderate $\mathrm{EN}(\mathrm{LN})$ event and $+(-) 4$ to generate a strong ENSO forcing. For moderate EN this yields a forcing peaking at about $1.5 \mathrm{~K}$ in the Niño3.4 region in DecemberJanuary-February (DJF) and below $0.5 \mathrm{~K}$ in summer (Figure 3a).

The climatological simulation is integrated for 150 years with a repeating SST seasonal cycle (Figure S1). The first 20 years are removed as spin-up. The four forced SST simulations (strong EN, moderate EN, moderate LN, strong LN, Figures 1a-1d) are initialized from the twentieth year of the climatological simulation and are run with the forced SST field for another 130 years, removing the first year as spin-up. This yields 129 years for each forced simulation.

The statistical significance of the EN and LN responses (forced minus climatological run) is assessed by a Monte Carlo approach using 1,000 random DJF mean pairs of the two samples.

The model results are compared to reanalysis data (JRA-55, 1958-2017; Kobayshi et al., 2015) and SST observations (NOAA ERSSTv4). In observations, EN (LN) events are selected when the ONDJF Niño3.4 mean standardized and detrended SST anomalies are above (below) $+(-) 1$ standard deviations. For strong events two standard deviations are used. More information about the identified years can be found in the supporting information.

\section{The North Pacific Response to A Linear SST Forcing}

In this section we analyze the winter Pacific circulation response to the four linear ENSO forcings. The precipitation response (Figures $1 \mathrm{e}-1 \mathrm{~h}$ ) indicates the stronger sensitivity in the $\mathrm{CP}$ as compared to the EP due to the critical convention threshold, for example, precipitation responses are stronger where SSTs reach values of more than $28^{\circ} \mathrm{C}$ (e.g., C. Zhang, 1993). The different SST forcings consist of increased (decreased) precipitation in the $\mathrm{CP}$ and drier (wetter) than normal conditions over the maritime continent for EN (LN). North-south asymmetries also exist, for example, LN dry anomalies show a stronger signal south of the equator, whereas EN enhanced precipitation is mainly centered over the equator on the westward flank of the warmest SST values. Similar precipitation responses are found in observations and JRA-55 composites (Figure S3), however the SST anomaly patterns change substantially between EN and LN and their respective strengths.

Boreal winter mean (DJF) precipitation anomalies in the equatorial region are directly linked to deep convection and divergence at upper levels (Wang, 2004). The maximum upper level divergence during EN coincides with the location of the maximum precipitation response (Figures $2 \mathrm{a}$ and $2 \mathrm{~b}$ ). The opposite sign response is found for LN (Figures $2 \mathrm{c}$ and $2 \mathrm{~d}$ ), however the convergence anomalies are shifted slightly southward in the model. JRA-55 reanalysis (Figure S4) exhibits comparable patterns, with a small westward shift for LN due to its more westward location.

The model is also able to correctly reproduce the sign and general shape of the teleconnection to the North Pacific in terms of sea level pressure (SLP), that is, a deepening (weakening) and eastward extension (retraction) of the climatological AL during EN (LN) conditions (Figures 2e-2h). The AL SLP also exhibits nonlinear behavior with respect to the SST forcing, that is, the strong EN forcing induces significantly stronger anomalies in comparison to the strong LN forcing. At upper levels the model reproduces a positive (negative) PNA pattern and a southward (northward) shift and strengthening (weakening) of the upper level tropospheric jet during EN (LN) conditions (see Figure S2 for the geopotential height and upper level wind responses). Another interesting feature is the longitudinal shift of the SLP (Figures 2e-2h) and the $250 \mathrm{hPa}$ geopotential height (Figures S2a-2d) response, which cannot be attributed to the SST forcing, as such a longitudinal shift is not present in the forced SST anomalies. The SLP minimum/maximum anomaly in the $\mathrm{AL}$ region shifts from $214^{\circ} \mathrm{E}$ for strong $\mathrm{EN}$ to $200^{\circ} \mathrm{E}$ for strong $\mathrm{LN}$ (see also Table $\mathrm{S} 2$ for intermediate values). This shift is also found in observations, but only for the EN phase (Figures S4e and S4f), however this signal is not statistically robust and we cannot distinguish the relative contribution of the strength and location of the SST forcing, as stronger events are associated with an eastward shift of the SST anomalies due to atmosphere-ocean feedbacks (Bayr et al., 2018; Frauen \& Dommenget, 2010).

In order to evaluate the impact of the forcing in the seasonal evolution, we now define two area averaged indices: poleward divergent wind at $150 \mathrm{hPa}$ in the tropics and SLP in the AL region (see regions indicated 
Divergence \& Div. Wind at $150 \mathrm{hPa}$

(a)

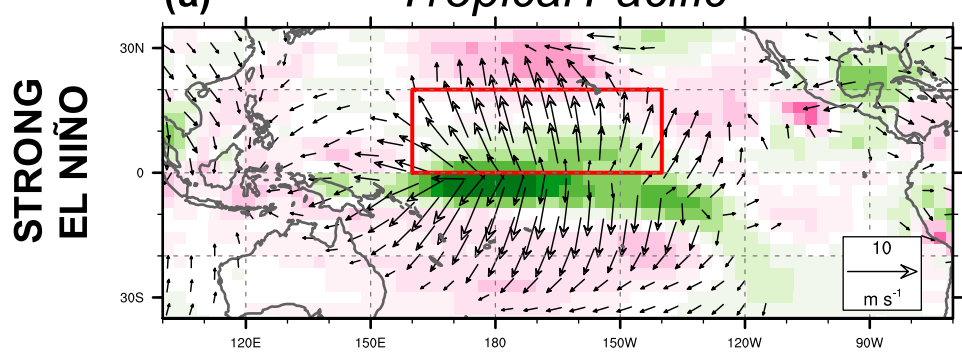

(b)

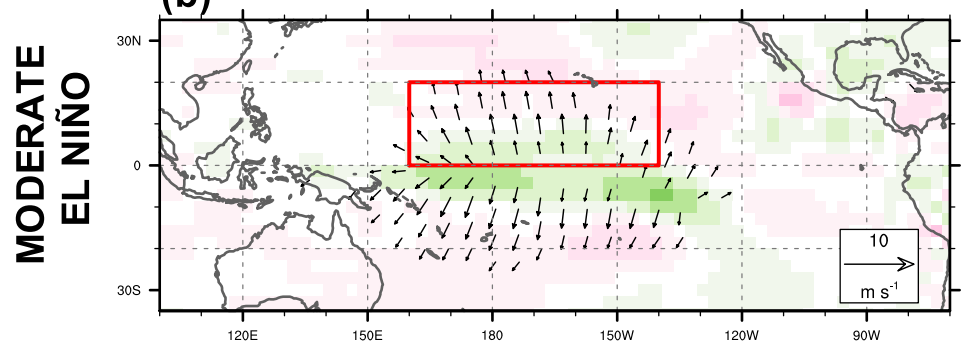

(c)

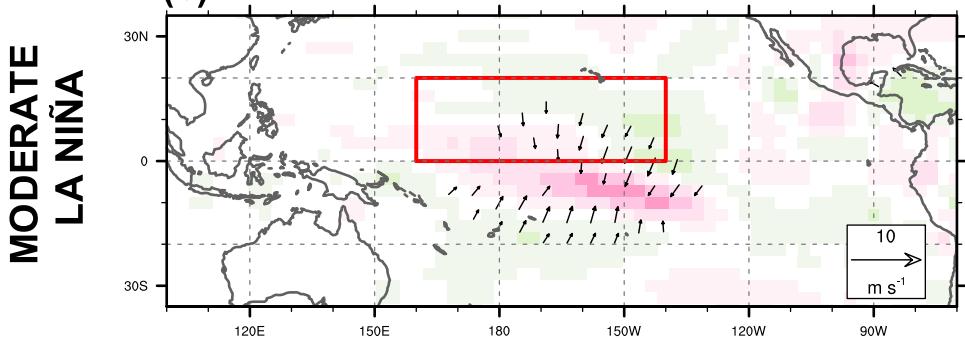

(d)

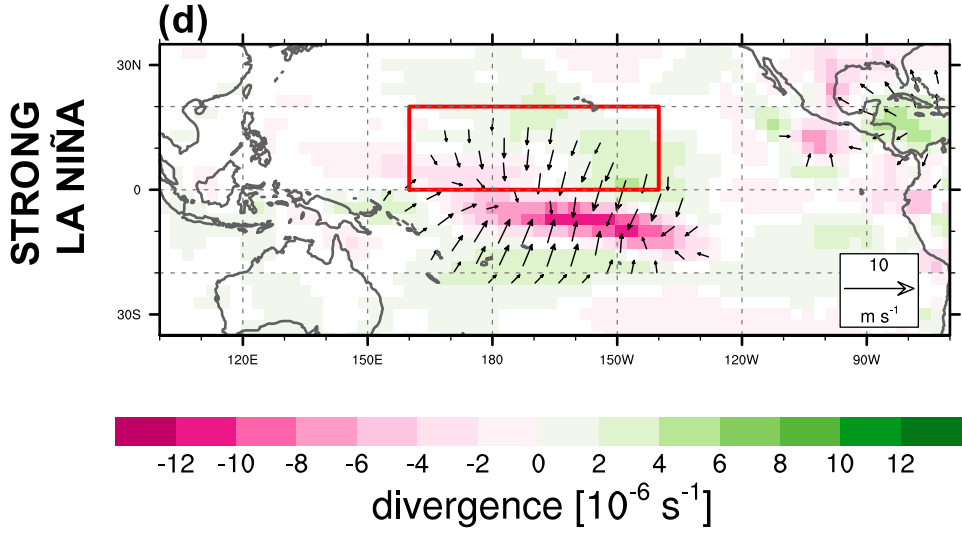

Sea Level Pressure North Pacific

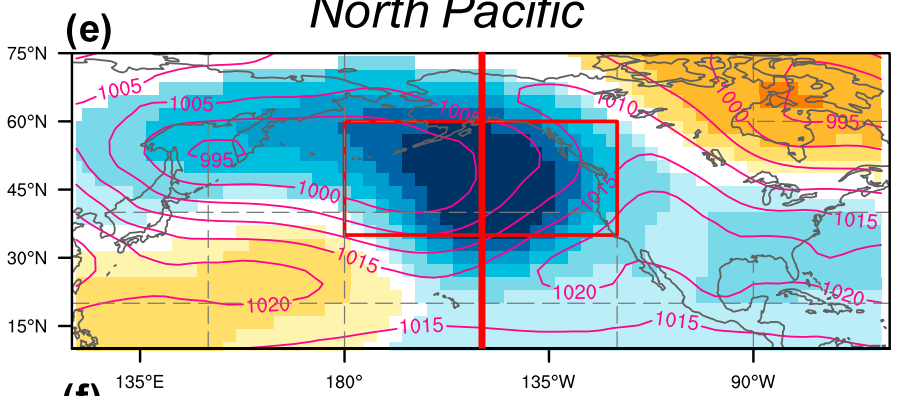

(f)

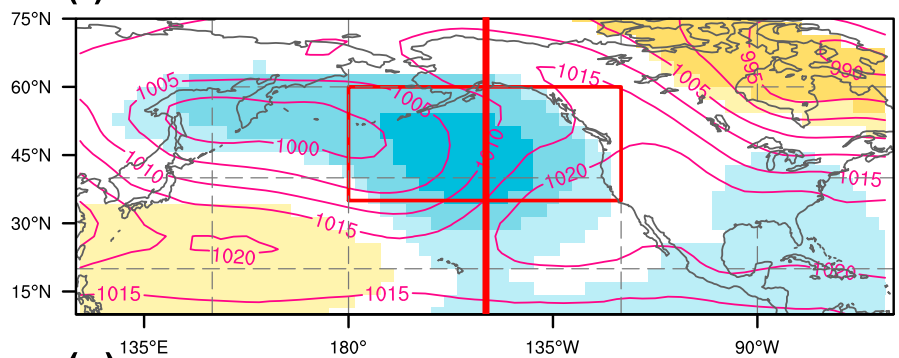

(g)

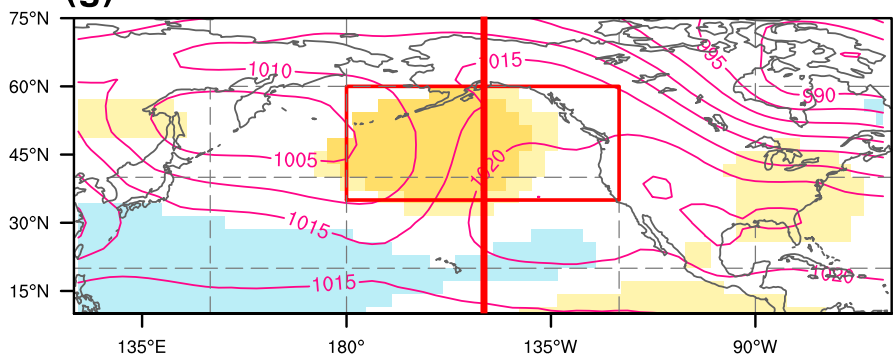

(h)

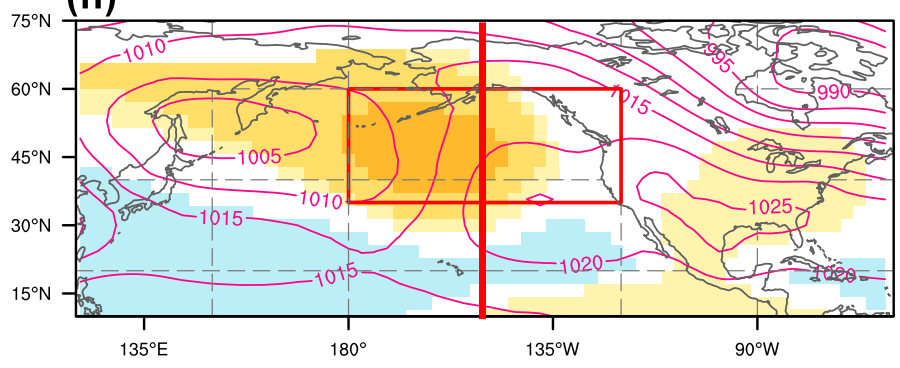

$\begin{array}{lllllllllll}-10 & -8 & -6 & -4 & -2 & 0 & 2 & 4 & 6 & 8 & 10\end{array}$

Figure 2. (a-d) December-January-February mean divergence (shading) and the associated divergent wind (arrows) response at $150 \mathrm{hPa}$ and (e-h) December-January-February mean SLP response (shading) and total field (contours) in the North Pacific region, for (a, e) strong and (b, f) moderate El Niño and for $(c, g)$ moderate and $(d, h)$ strong La Niña forcing. Red boxes indicate the area where (a-d) the meridional divergent wind and (e-h) the Aleutian low SLP indices are defined, that is, $\left[0-20^{\circ} \mathrm{N}, 160-220^{\circ} \mathrm{E}\right]$ and $\left[35-60^{\circ} \mathrm{N}, 180-240^{\circ} \mathrm{E}\right]$, respectively. Only statistically significant values above the $99 \%$ confidence level are shown. The vertical line in (e)-(h) is placed at $210^{\circ} \mathrm{E}$ and is used as a reference to better visualize the longitudinal shift in the SLP anomalies. SLP $=$ sea level pressure.

in Figure 2). While the forced SSTs are linearly spaced by design (Figure 3a), the divergent wind response (Figure 3b) exhibits nonlinear behavior with respect to the forcing. For moderate events, there is a slightly stronger anomaly during EN than during LN (asymmetry). For strong EN the poleward divergent wind response exhibits more than double the magnitude (of opposite sign) of strong LN forcing. AL SLP anomalies exhibit a more complex behavior (Figure 3c) due to the higher interannual variability (shaded area) as compared to the tropics. For strong EN events (red line in Figure 3c) SLP anomalies in the eastern North 
(a) NINO3.4 SST anomalies

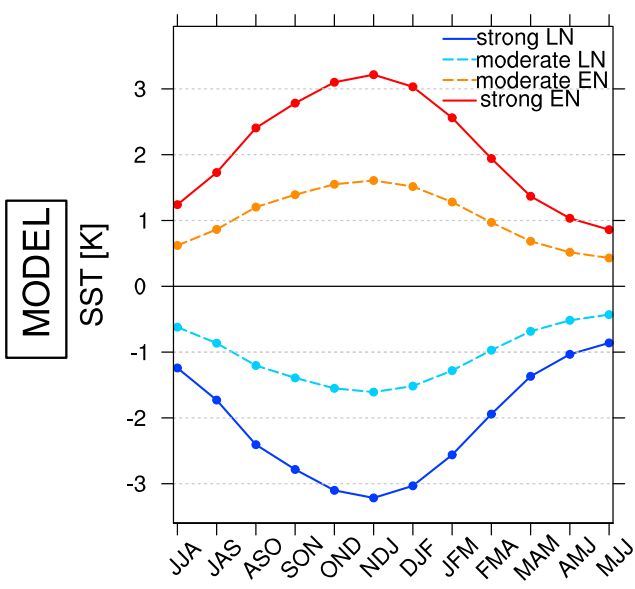

(d) NINO3.4 SST anomalies (ERSSTv4)

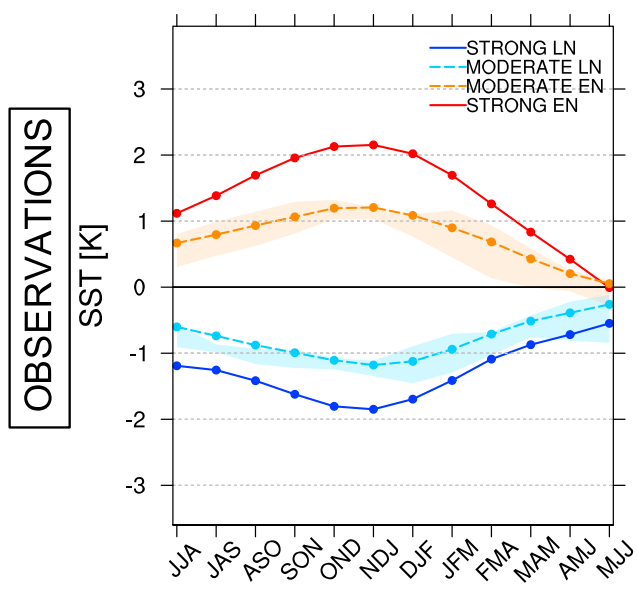

(b) meridional divergent wind anomalies

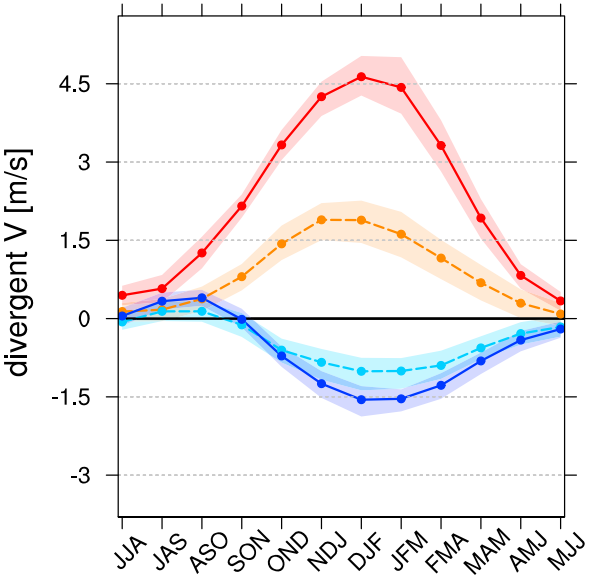

(e) meridional divergent wind anomalies (JRA-55)

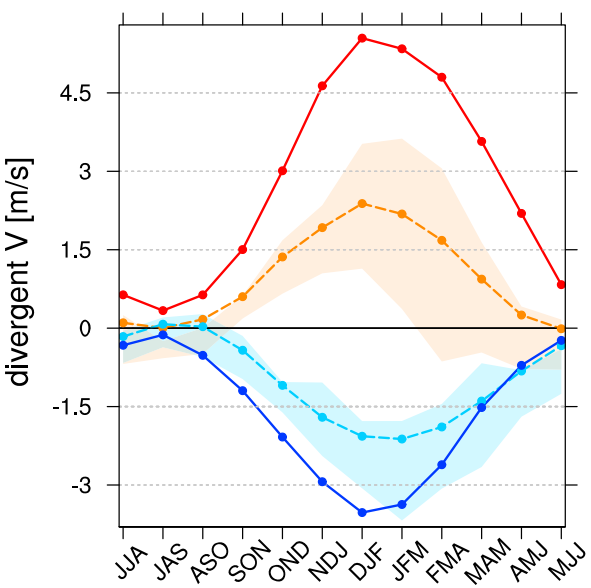

(c) Aleutian Low SLP anomalies

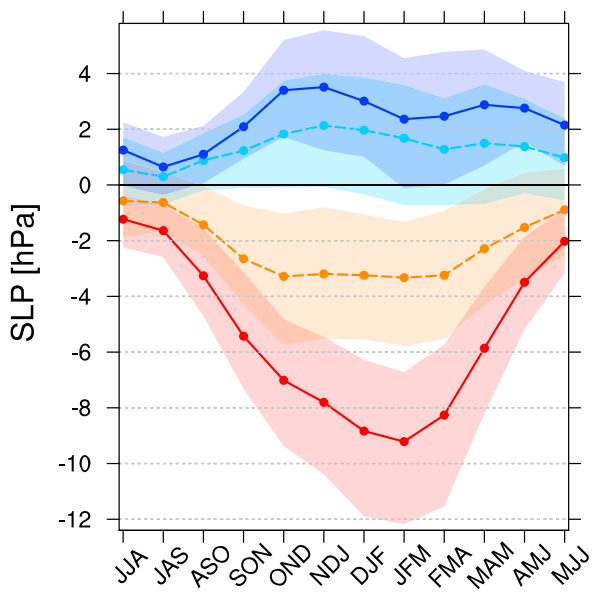

(f) Aleutian Low SLP anomalies (JRA-55)

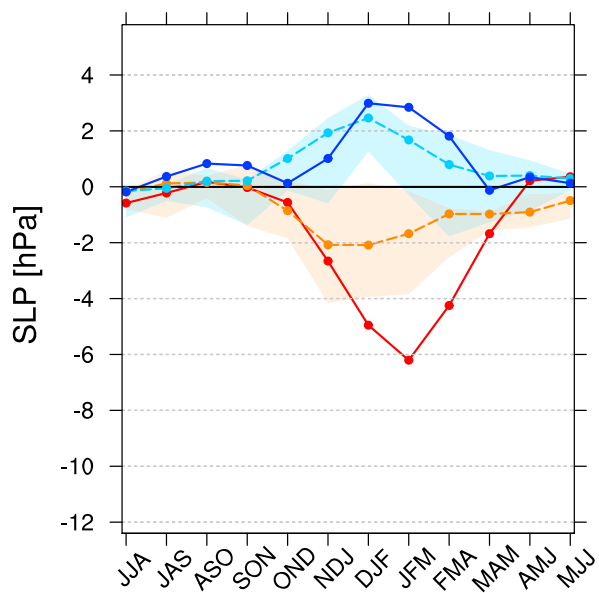

Figure 3. Seasonal evolution of the 3-month running mean of (a, d) the Niño3.4 index anomalies, (b, e) the meridional divergent wind index response, and $(c, f)$ the Aleutian low SLP index response. Shading upper and lower limits display the upper and lower quartiles, respectively. Different colors indicate the different SST forcing experiments. The indices are computed by averaging over the boxes in Figures 1 and 2. Panles (c)-(e) the same as in (a)-(c) but for observations and reanalysis data. No shading is indicated for strong events due to the limited number of events. SST = sea surface temperature; LN = La Niña; EN = El Niño; SLP = sea level pressure; JJA = June-July-August; JAS = July-August-September; ASO = August-September-October;

SON = September-October-November; OND = October-November-December; NDJ = November-December-January; DJF = December-January-February; JFM = January-February-March; FMA = February-March-April; MAM = March-April-May; AMJ = April-May-June; MJJ = May-June-July.

Pacific almost reach $-10 \mathrm{hPa}$ in January-February-March (JFM), whereas for moderate events they only reach $-3 \mathrm{hPa}$. For moderate LN the DJF SLP anomalies reach around $2 \mathrm{hPa}$ and for strong LN only slightly over $3 \mathrm{hPa}$. The peak in SST anomalies is in December (see NDJ mean), while for the upper divergent wind the response peaks 1 month later (DJF). A similar behavior is observed in reanalysis (Figures 3e and 3f), despite a weaker North Pacific SLP response. However a direct comparison is not possible due to the additional factors influencing this response in reanalysis and the lack of statistical robustness, mainly for strong events. In reanalysis (Figure 3f) the peak in the SLP anomalies takes place in DJF for both EN and LN, except for strong EN events where the response peaks in JFM, while in the model experiments (Figure 3c) significant anomalies extend from October until May. Despite these differences, the overall DJF signal is well reproduced in the model. Note the larger variability in the extreme events.

The origin of the nonlinearities in the model experiments can now be assessed for the different steps in the pathway. The relationship between the DJF Niño3.4 SST anomalies and the tropical divergent wind (Figures 4a and 4b) is approximately linear for moderate events but diverges from a linear relationship for strong events (larger Root mean squared error [RMSE]). This is also the case for observations, although a 

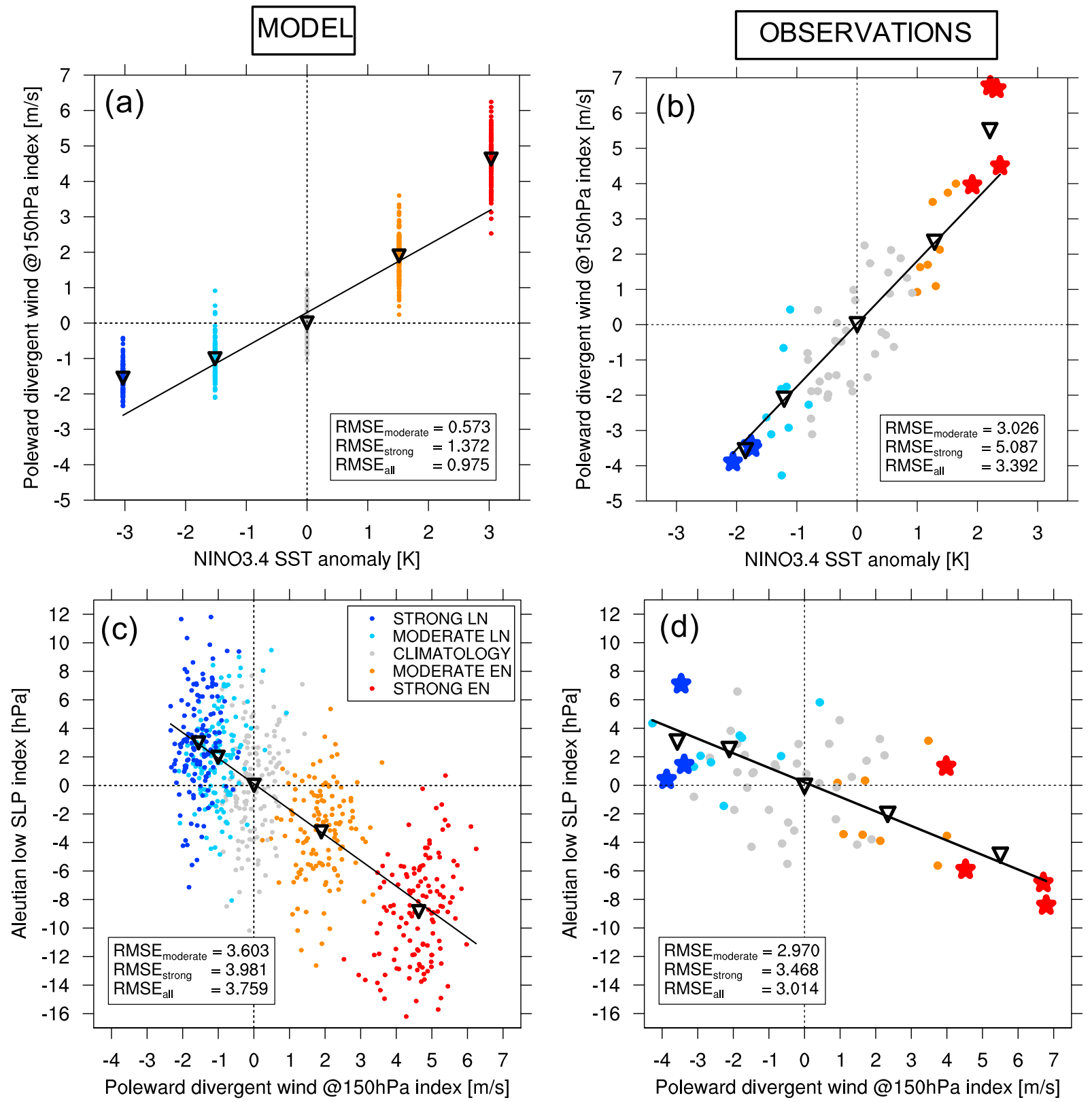

Figure 4. (a) Isca model and (b) JRA-55 reanalysis December-January-February tropical upper troposphere poleward divergent wind anomaly index with respect to the Niño3.4 anomaly. Panels (c) and (d) as in panels (a) and (b) but for the poleward divergent wind and the Aleutian low SLP anomaly indices, respectively. Colors in (a) and (c) indicate the different SST forcing experiments and in (b) and (d) the classification of the observed El Niño Southern Oscillation events. Black triangles show the composite mean for each forcing/classification and the black line is the regression using only climatology/neutral and moderate events. The RMSE values between the linear fit and moderate, strong and all events are shown for each panel. In (b) and (d) stars indicate strong events (see Table S1 for the corresponding years). The indices are computed by averaging over the boxes in Figure 2 . SLP $=$ sea level pressure; SST $=$ sea surface temperature; LN = La Niña; EN = El Niño.

more linear behavior is observed for strong LN. This is related to the asymmetry of the SST pattern between LN and EN in observations, which by design is not present in our model simulations. In contrast, the relationship between tropical divergence and the extratropical SLP is more linear (Figures $4 \mathrm{c}$ and $4 \mathrm{~d}$ ). In particular, for the model simulations the change in RMSE is smaller when comparing moderate and strong events. This is a strong evidence that most of the SLP nonlinear response for strong EN events (see also Figure S5 for the SST-SLP relationship) has its origin in the tropical convective response to the underlying SST anomalies. 
(a) $2 x(\bmod$. EN + mod. LN)

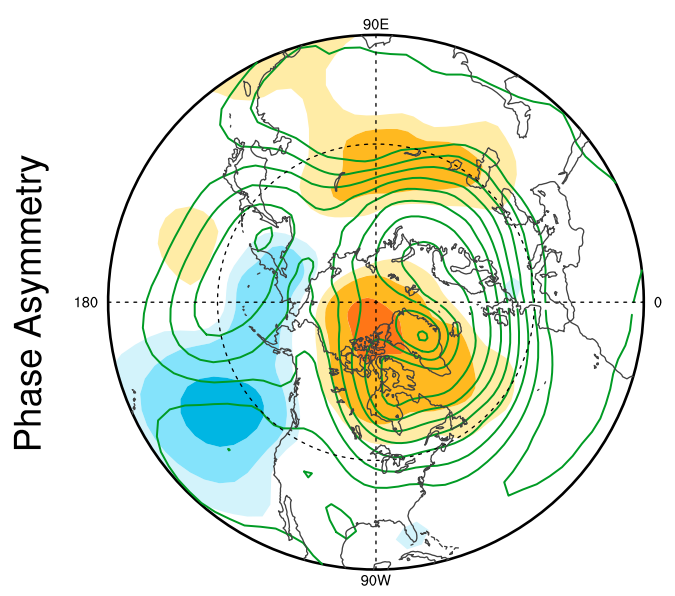

(c) strong EN - 2x(mod. EN)

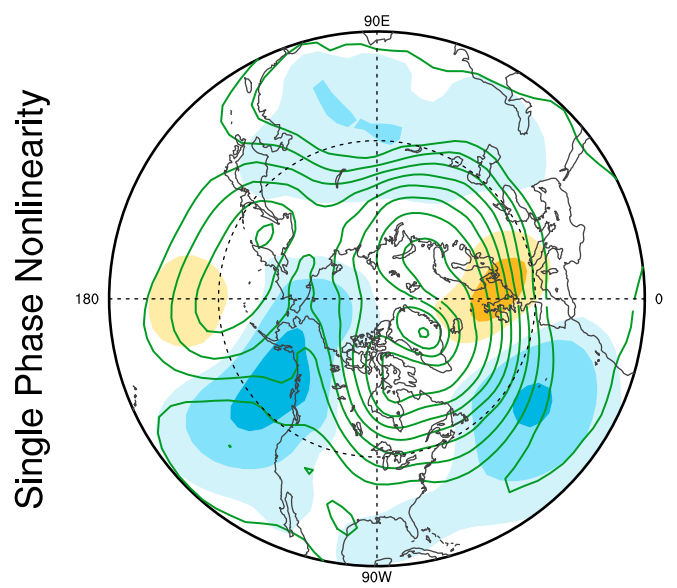

(b) strong EN + strong LN

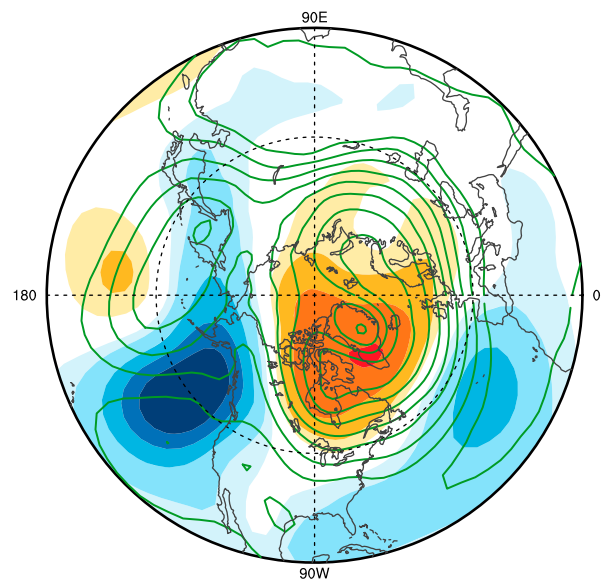

(d) strong LN - 2x(mod. LN)

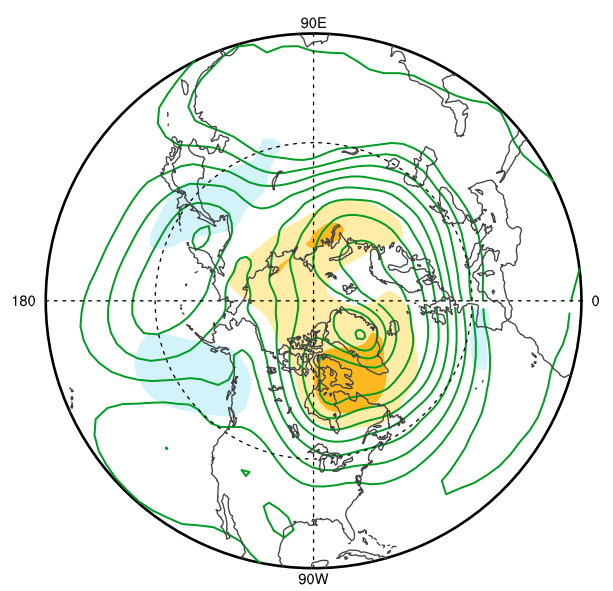

[hPa]

Figure 5. December-January-February model sea level pressure response asymmetry for (a) twice the moderate and (b) strong El Niño Southern Oscillation forcings. (c) EN and (d) LN single phase nonlinearity. Green contours indicate climatological values computed from the climatological simulation. The contour interval is $5 \mathrm{hPa}$. EN = El Niño; LN = La Niña.

\section{Spatial Pattern of the Northern Hemisphere Nonlinear Response to ENSO}

We now examine in more detail the spatial pattern of the nonlinear response to the ENSO SST forcing. We focus on SLP DJF averages over the Northern Hemisphere (Figure 5), while the same analysis for geopotential height at $250 \mathrm{hPa}$ yields comparable results (Figure S6). The sum of the EN and LN responses is a measure of the asymmetry between the two ENSO phases. If the response was exactly symmetric the sum of the anomalies would cancel everywhere as the SST forcing is exactly symmetric. However, the asymmetry is found to be stronger (more than double) for strong events (Figure 5b) than for moderate events (Figure 5a). For moderate events the strongest asymmetry is found in the eastern North Pacific, coincident with the strongest response to the SST forcing (Figures 2e-2h). This is an indication of a stronger sensitivity to an AL-PNA projection for EN than for LN. For a strong ENSO forcing, the asymmetry is more than $8 \mathrm{hPa}$ in the eastern North Pacific and extends well into the North Atlantic. The negative North Atlantic Oscillation (NAO) pattern signature in the Atlantic is only observed for strong EN forcing (not shown) and is much weaker during strong LN, similar to what is found in reanalysis (Jiménez-Esteve \& Domeisen, 2018).

We quantify the nonlinearity between moderate and strong EN and LN events by multiplying the response to moderate events by a factor of two and subtracting it from the strong event response. For an exactly linear 
response this would yield zero. However, for EN (Figure 5c) a zonal wave train pattern emerges (clearer at upper levels, see Figure S6c). The pattern also indicates that the AL deepening during a strong forcing is more than double that for moderate events and located further eastward (denoted by a dipole structure). In the North Atlantic, a negative NAO dipole anomaly suggests the existence of nonlinear eddy feedbacks that strengthen the negative NAO during strong ENSO events (e.g., Jiménez-Esteve \& Domeisen, 2018; Li \& Lau, 2012). LN (Figure 5d) displays a weaker absolute nonlinearity and a saturation of the response in the eastern North Pacific and PNA centers (Figure S6), which can be explained in terms of the nonlinear relationship between SSTs and the tropical upper level divergent wind (Figure 4a) plus the linear relationship between divergent wind and the extratropical SLP response (Figure 4c).

\section{Discussion and Conclusions}

Idealized model experiments with a seasonally evolving SST forcing have been performed to explore the response of the North Pacific to a linear change in the amplitude of a longitudinally fixed ENSO-like SST forcing, thereby removing nonlinearities arising from a change in the longitudinal location of the maximum SST anomalies. The extratropical SSTs are forced by climatological values in order to remove potential nonlinearities arising from extratropical effects.

A nonlinear relationship between the amplitude of the SST forcing and the North Pacific SLP can be observed. Nonlinearities are observed in both the pattern and strength of the tropical precipitation and upper level divergent winds, mainly for strong ENSO events. These nonlinearities "propagate" to the North Pacific, where a deeper (weaker) AL is observed during EN (LN) forcings. The origin of the nonlinearity can be traced back to the known nonlinear relationship between SST and convection in the tropics, while the relationship between upper level divergent wind anomalies and the North Pacific SLP response is found to be more linear in winter (DJF). The strongest SLP nonlinear response is located in the far northeastern Pacific, agreeing with previous results (e.g., Garfinkel et al., 2018).

The main result of our study is that the North Pacific nonlinearities in both amplitude and location can arise independently of any variation in longitudinal location of the ENSO SST anomalies in the tropical Pacific. While in observations, the variability in the location of the tropical SST forcing (CP vs EP) can contribute to nonlinearity (e.g., Frauen et al., 2014; Yu et al., 2012), longitudinal shifts in the North Pacific are here shown to arise solely through changes in amplitude and not through longitudinal shifts in the SST forcing in the tropical Pacific. In addition, ocean-atmosphere feedbacks, the interaction with other sources of variability, like the Madden-Julian Oscillation (e.g., Hoell et al., 2014), or longer term variability (Domeisen et al., 2018) can also be sources of nonlinearity. The simplified model runs allow us to directly quantify the nonlinear response arising solely from atmospheric processes responding to a linear change in the amplitude of the SST forcing fixed in location. In this work we used the Niño-3.4 region, which is more sensitive to EP events and which Frauen et al. (2014) and Garfinkel et al. (2018) found to exhibit a higher nonlinearity in the North Pacific than CP events. Frauen et al. (2014) found that the observed linear response in the North Pacific is due to a combination of EP and CP ENSO events, therefore ENSO diversity may lead to a reduction in the nonlinear North Pacific SLP response that is observed for SST anomalies in a fixed location, that is, CP or EP EN events evaluated separately. On the other hand, coupled models tend to underestimate the degree of nonlinearity of teleconnections as compared to observations (Domeisen et al., 2018), indicating that the magnitude of the modeled nonlinearities may differ in the real world.

We also found a longer seasonal extratropical SLP response compared to reanalysis, the response is present from October to May in the model, while in observations it is confined to December-March. This could be due to the lack of realism of a repeating seasonal cycle of the forcing. While in the simulations the climatological AL is slightly weaker and more westward than in observations, we nevertheless find that this does not affect the main conclusions of this study, as the model teleconnection SLP response to ENSO agrees well with reanalysis.

The model results also show important nonlinearities in the North Atlantic sector, mainly between strong EN and LN events, as suggested by Brönnimann (2007) and W. Zhang et al., (2018). We suggest that nonlinearities in the North Pacific may impact the downstream flow in the North Atlantic via tropospheric mechanisms such as the anomalous propagation of transient eddies (e.g., Drouard et al., 2015; Jiménez-Esteve \& Domeisen, 2018; Li \& Lau, 2012) and changes in cyclogenesis (Schemm et al., 2018), as well as through the stratosphere (Butler et al., 2014; Domeisen et al., 2015; Ineson \& Scaife, 2009). Thus, further research will help to understand the different pathways as well as nonlinearities associated with the impact of ENSO teleconnections on the North Atlantic and Europe. 


\section{Acknowledgments}

The authors would like to thank Stephen Thomson for his help regarding the model setup and validation. Support from the Swiss National Science Foundation through project PP00P2_170523 is gratefully acknowledged. The ISCA modeling framework has been downloaded from the Github repository (https://github.com/ExeClim/Isca). The JRA-55 reanalysis and the ERSSTV4 data were downloaded from the NCAR research data archive (https://rda.ucar.edu/) and the ERA-Interim reanalysis has been obtained from the ECMWF server (https://apps.ecmwf.int/datasets/data/). We also thank the two anonymous reviewers for their helpful comments.

\section{References}

An, S. I. (2004). Interdecadal changes in the El Nino-La Nina asymmetry. Geophysical Research Letters, 31, L23210. https://doi.org/10.1029/ 2004GL021699

An, S. I., \& Jin, F. F. (2004). Nonlinearity and asymmetry of ENSO. Journal of Climate, 17(12), 2399-2412. https://doi.org/10.1175/ 1520-0442(2004)017<2399:NAAOE > 2.0.CO;2

Ashok, K., Behera, S. K., Rao, S. A., Weng, H., \& Yamagata, T. (2007). El Niño Modoki and its possible teleconnection. Journal of Geophysical Research, 112, C11007. https://doi.org/10.1029/2006JC003798

Bayr, T., Latif, M., Dommenget, D., Wengel, C., Harlaß, J., \& Park, W. (2018). Mean-state dependence of ENSO atmospheric feedbacks in climate models. Climate Dynamics, 50(9-10), 3171-3194. https://doi.org/10.1007/s00382-017-3799-2

Bjerknes, J. (1969). Atmospheric teleconnections from the equatorial Pacific. Monthly Weather Review, 97(3), 163-172. https://doi.org/ 10.1175/1520-0493(1969)097<0163:ATFTEP>2.3.CO;2

Brönnimann, S (2007). Impact of El Niño-Southern Oscillation on European climate. Reviews of Geophysics, 45, RG3003. https://doi.org/ 10.1029/2006RG000199

Butler, A. H., Polvani, L. M., \& Deser, C. (2014). Separating the stratospheric and tropospheric pathways of El Niño-Southern Oscillation teleconnections. Environmental Research Letters, 9(2), 9. https://doi.org/10.1088/1748-9326/9/2/024014

Cai, W., Borlace, S., Lengaigne, M., Van Rensch, P., Collins, M., Vecchi, G., et al. (2014). Increasing frequency of extreme El Niño events due to greenhouse warming. Nature Climate Change, 4(2), 111-116. https://doi.org/10.1038/nclimate2100

Cai, W., Wang, G., Dewitte, B., Wu, L., Santoso, A., Takahashi, K., et al. (2018). Increased variability of eastern Pacific El Niño under greenhouse warming. Nature, 564(7735), 201-206.

Capotondi, A., Wittenberg, A. T., Newman, M., Di Lorenzo, E., Yu, J. Y., Braconnot, P., et al. (2015). Understanding ENSO diversity. Bulletin of the American Meteorological Society, 96(6), 921-938. https://doi.org/10.1175/BAMS-D-13-00117.1

Chiodi, A. M., \& Harrison, D. E. (2013). El Niño impacts on seasonal US atmospheric circulation, temperature, and precipitation anomalies: The OLR-event perspective. Journal of Climate, 26(3), 822-837. https://doi.org/10.1175/JCLI-D-12-00097.1

Chung, C. T. Y., \& Power, S. B. (2015). Modelled rainfall response to strong El Niño sea surface temperature anomalies in the tropical Pacific. Journal of Climate, 28(8), 3133-3151. https://doi.org/10.1175/JCLI-D-14-00610.1

Dee, D. P., Uppala, S. M., Simmons, A. J., Berrisford, P., Poli, P., Kobayashi, S., et al. (2011). The ERA-Interim reanalysis: Configuration and performance of the data assimilation system. Quarterly Journal of the Royal Meteorological Society, 137(656), 553-597. https://doi.org/ 10.1002/qj.828

Deser, C., Simpson, I. R., McKinnon, K. A., \& Phillips, A. S. (2017). The Northern Hemisphere extratropical atmospheric circulation response to ENSO: How well do we know it and how do we evaluate models accordingly? Journal of Climate, 30(13), 5059-5082. https://doi.org/10.1175/JCLI-D-16-0844.1

Deser, C., Simpson, I. R., Phillips, Adam. S., \& McKinnon, K. A. (2018). How well do we know ENSO's climate impacts over North America, and how do we evaluate models accordingly? Journal of Climate, 31(13), 4991-5014. https://doi.org/10.1175/JCLI-D-17-0783.1

Domeisen, D. I. V., Butler, A. H., Fröhlich, K., Bittner, M., Müller, W. A., \& Baehr, J. (2015). Seasonal predictability over Europe arising from El Niño and stratospheric variability in the MPI-ESM seasonal prediction system. Journal of Climate, 28(1), 256-271. https://doi.org/10.1175/JCLI-D-14-00207.1

Domeisen, D. I. V., Garfinkel, C. I., \& Butler, A. H. (2018). The teleconnection of El Niño Southern Oscillation to the stratosphere. Reviews of Geophysics, 57. https://doi.org/10.1029/2018RG000596

Dommenget, D., Bayr, T., \& Frauen, C. (2013). Analysis of the non-linearity in the pattern and time evolution of El Niño Southern Oscillation. Climate Dynamics, 40(11-12), 2825-2847. https://doi.org/10.1007/s00382-012-1475-0

Drouard, M., Rivière, G., \& Arbogast, P. (2015). The link between the North Pacific climate variability and the North Atlantic Oscillation via downstream propagation of synoptic waves. Journal of Climate, 28, 3957-3976. https://doi.org/10.1175/JCLI-D-14-00552.1

Franzke, C., \& Feldstein, S. B. (2005). The continuum and dynamics of Northern Hemisphere teleconnection patterns. Journal of the Atmospheric Sciences, 62(9), 3250-3267. https://doi.org/10.1175/JAS3536.1

Frauen, C., \& Dommenget, D. (2010). El Niño and La Niña amplitude asymmetry caused by atmospheric feedbacks. Geophysical Research Letters, 37, L18801. https://doi.org/10.1029/2010GL044444

Frauen, C., Dommenget, D., Tyrrell, N., Rezny, M., \& Wales, S. (2014). Analysis of the nonlinearity of El Niño-Southern Oscillation teleconnections. Journal of Climate, 27(16), 6225-6244. https://doi.org/10.1175/JCLI-D-13-00757.1

Garfinkel, C. I., Hurwitz, M. M., Waugh, D. W., \& Butler, A. H. (2013). Are the teleconnections of Central Pacific and Eastern Pacific El Niño distinct in boreal wintertime? Climate Dynamics, 41(7-8), 1835-1852. https://doi.org/10.1007/s00382-012-1570-2

Garfinkel, C. I., Weinberger, I., White, I. P., Oman, L. D., Aquila, V., \& Lim, Y.-K. (2018). The salience of nonlinearities in the boreal winter response to ENSO: North Pacific and North America. Climate Dynamics, O(0), 1-18. https://doi.org/10.1007/s00382-018-4386-x

Geen, R., Lambert, F. H., \& Vallis, G. K. (2018). Regime change behavior during Asian monsoon onset. Journal of Climate, 31(8), $3327-3348$. https://doi.org/10.1175/JCLI-D-17-0118.1

Halpert, M. S., \& Ropelewski, C. F. (1992). Surface temperature patterns associated with the Southern Oscillation. Journal of Climate, 5(6), 577-593. https://doi.org/10.1175/1520-0442(1992)005<0577:STPAWT>2.0.CO;2

Hoell, A., Barlow, M., Wheeler, M. C., \& Funk, C. (2014). Disruptions of El Niño-Southern Oscillation teleconnections by the Madden-Julian Oscillation. Geophysical Research Letters, 41, 998-1004. https://doi.org/10.1002/2013GL058648

Hoerling, M. P., \& Kumar, A. (2002). Atmospheric response patterns associated with tropical forcing. Journal of Climate, 15(16), 2184-2203. https://doi.org/10.1175/1520-0442(2002)015<2184:ARPAWT>2.0.CO;2

Hoerling, M. P., Kumar, A., Xu, T., Hoerling, M. P., Kumar, A., \& Xu, T. (2001). Robustness of the nonlinear climate response to ENSO's extreme phases. Journal of Climate, 14(6), 1277-1293. https://doi.org/10.1175/1520-0442(2001)014<1277:ROTNCR>2.0.CO;2

Hoerling, M. P., Kumar, A., \& Zhong, M. (1997). El Niño, La Niña, and the nonlinearity of their teleconnections. Journal of Climate, 10(8), 1769-1786. https://doi.org/10.1175/1520-0442(1997)010<1769:ENOLNA>2.0.CO;2

Horel, J. D., \& Wallace, J. M. (1981). Planetary-scale atmospheric phenomena associated with the Southern Oscillation. Monthly Weather Review, 109(4), 813-829.

Hoskins, B. J., \& Karoly, D. J. (1981). The steady linear response of a spherical atmosphere to thermal and orographic forcing. Journal of the Atmospheric Sciences, 38(6), 1179-1196. https://doi.org/10.1175/1520-0469(1981)038<1179:TSLROA >2.0.CO;2

Huang, B., Banzon, V. F., Freeman, E., Lawrimore, J., Liu, W., Peterson, T. C., et al. (2015). Extended reconstructed sea surface temperature version 4 (ERSST.v4). Part I: Upgrades and intercomparisons. Journal of Climate, 28(3), 911-930. https://doi.org/10.1175/ JCLI-D-14-00006.1 
Ineson, S., \& Scaife, A. (2009). The role of the stratosphere in the European climate response to El Niño. Nature Geoscience, 2(1), 32-36. https://doi.org/10.1038/ngeo381

Infanti, J. M., \& Kirtman, B. P. (2016). North American rainfall and temperature prediction response to the diversity of ENSO. Climate Dynamics, 46(9-10), 3007-3023. https://doi.org/10.1007/s00382-015-2749-0

Jiménez-Esteve, B., \& Domeisen, D. I. V. (2018). The tropospheric pathway of the ENSO-North Atlantic teleconnection. Journal of Climate, 31(11), 4563-4584. https://doi.org/10.1175/JCLI-D-17-0716.1

Johnson, N. C., \& Kosaka, Y. (2016). The impact of eastern equatorial Pacific convection on the diversity of boreal winter El Niño teleconnection patterns. Climate Dynamics, 47(12), 3737-3765. https://doi.org/10.1007/s00382-016-3039-1

Jong, B.-T., Ting, M., \& Seager, R. (2016). El Niño's impact on California precipitation: Seasonality, regionality, and El Niño intensity. Environmental Research Letters, 11(5), 054021. https://doi.org/10.1088/1748-9326/11/5/054021

Kobayshi, S., Ota, Y., Harada, Y., Ebita, A., Moriya, M., Onoda, H., et al. (2015). The JRA-55 reanalysis: General specifications and basic characteristics. Journal of the Meteorological Society of Japan Series II, 93(1), 5-48. https://doi.org/10.2151/jmsj.2015-001

Kug, J.-S., \& Ham, Y.-G. (2011). Are there two types of La Nina? Geophysical Research Letters, 38, L16704. https://doi.org/10.1029/ 2011GL048237

Latif, M., \& Keenlyside, N. S. (2009). El Niño/Southern Oscillation response to global warming. Proceedings of the National Academy of Sciences of the United States of America, 106(49), 20,578-20,583. https://doi.org/10.1073/pnas.0710860105

Leathers, D. J., \& Palecki, M. A. (1992). The Pacific/North American teleconnection pattern and United States climate. Part II: Temporal characteristics and index specification. Journal of Climate, 5(7), 707-716. https://doi.org/10.1175/1520-0442(1992)005< 0707:TPATPA > 2.0.CO;2

Leathers, D. J., Yarnal, B., \& Palecki, M. A. (1991). The Pacific/North American teleconnection pattern and United States climate. Part I: Regional temperature and precipitation associations. Journal of Climate, 4(5), 517-528. https://doi.org/10.1175/1520-0442(1991)004< 0517:TPATPA>2.0.CO;2

Li, Y., \& Lau, N. C. (2012). Impact of ENSO on the atmospheric variability over the North Atlantic in late winter-Role of transient eddies. Journal of Climate, 25(1), 320-342. https://doi.org/10.1175/JCLI-D-11-00037.1

Liu, Z., \& Alexander, M. (2007). Atmospheric bridge, oceanic tunnel, and global climatic teleconnections. Reviews of Geophysics, 45 , RG2005. https://doi.org/10.1029/2005RG000172

Mo, K. C., \& Livezey, R. E. (1986). Tropical-extratropical geopotential height teleconnections during the Northern Hemisphere winter. Monthly Weather Review, 114(12), 2488-2515. https://doi.org/10.1175/1520-0493(1986)114<2488:TEGHTD>2.0.CO;2

Philander, S. G. H. (1990). El Niño, La Niña, and the Southern Oscillation. Cambridge, MA: Academic Press.

Ropelewski, C. F., \& Halpert, M. S. (1987). Global and regional scale precipitation patterns associated with the El Niño/Southern Oscillation. Monthly Weather Review, 115(8), 1606-1626. https://doi.org/10.1175/1520-0493(1987)115<1606:GARSPP>2.0.CO;2

Sardeshmukh, P. D., \& Hoskins, B. J. (1988). The generation of global rotational flow by steady idealized tropical divergence. Journal of the Atmospheric Sciences, 45(7), 1228-1251. https://doi.org/10.1175/1520-0469(1988)045<1228:TGOGRF>2.0.CO;2

Schemm, S., Rivière, G., Ciasto, L. M., \& Li, C. (2018). Extratropical cyclogenesis changes in connection with tropospheric ENSO teleconnections to the North Atlantic: Role of stationary and transient waves. Journal of the Atmospheric Sciences, 75(11), 3943-3964. https://doi.org/10.1175/JAS-D-17-0340.1

Seager, R., Naik, N., Ting, M., Cane, M. A., Harnik, N., \& Kushnir, Y. (2010). Adjustment of the atmospheric circulation to tropical Pacific SST anomalies: Variability of transient eddy propagation in the Pacific-North America sector. Quarterly Journal of the Royal Meteorological Society, 136(647), 277-296. https://doi.org/10.1002/qj.588

Stan, C., Straus, D. M., Frederiksen, J. S., Lin, H., Maloney, E. D., \& Schumacher, C. (2017). Review of tropical-extratropical teleconnections on intraseasonal time scales. Reviews of Geophysics, 55, 902-937. https://doi.org/10.1002/2016RG000538

Taschetto, A. S., Rodrigues, R. R., Meehl, G. A., McGregor, S., \& England, M. H. (2016). How sensitive are the Pacific-tropical North Atlantic teleconnections to the position and intensity of El Niño-related warming? Climate Dynamics, 46(5-6), 1841-1860. https://doi.org/ 10.1007/s00382-015-2679-x

Thomson, S. I., \& Vallis, G. K. (2018a). Atmospheric response to SST anomalies. Part I: Background-state dependence, teleconnections, and local effects in winter. Journal of the Atmospheric Sciences, 75, 4107-4124. https://doi.org/10.1175/JAS-D-17-0297.1

Thomson, S. I., \& Vallis, G. K. (2018b). Atmospheric response to SST anomalies. Part II: background-state dependence, teleconnections, and local effects in summer. Journal of the Atmospheric Sciences, 75(12), 4125-4138.

Timmermann, A., An, S.-I., Kug, J.-S., Jin, F.-F., Cai, W., Capotondi, A., et al. (2018). El Niño-Southern Oscillation complexity. Nature, 559(7715), 535-545. https://doi.org/10.1038/s41586-018-0252-6

Timmermann, A., Oberhuber, J., Bacher, A., Esch, M., Latif, M., \& Roeckner, E. (1999). Increased El Niño frequency in a climate model forced by future greenhouse warming. Nature, 398(6729), 694-697. https://doi.org/10.1038/19505

Trenberth, K. E., Branstator, G. W., Karoly, D., Kumar, A., Lau, N.-C., \& Ropelewski, C. (1998). Progress during TOGA in understanding and modeling global teleconnections associated with tropical sea surface temperatures. Journal of Geophysical Research, 103(C7), 14,291-14,324. https://doi.org/10.1029/97JC01444

Vallis, G. K., Colyer, G., Geen, R., Gerber, E., Jucker, M., Maher, P., et al. (2018). Isca, v1.0: A framework for the global modelling of the atmospheres of Earth and other planets at varying levels of complexity. Geoscientific Model Development, 11(3), 843-859. https://doi.org/ 10.5194/gmd-11-843-2018

Wang, C. (2004). ENSO, Atlantic climate variability, and the Walker and Hadley circulations, The Hadley circulation: Present, past and future (pp. 173-202). Dordrecht, Netherlands: Springer. https://doi.org/10.1007/978-1-4020-2944-8_7

Yu, J.-Y., Zou, Y., Kim, S. T., \& Lee, T. (2012). The changing impact of El Niño on US winter temperatures. Geophysical Research Letters, 39, L15702. https://doi.org/10.1029/2012GL052483

Zhang, C. (1993). Large-scale variability of atmospheric deep convection in relation to sea surface temperature in the tropics. Journal of Climate, 6(10), 1898-1913. https://doi.org/10.1175/1520-0442(1993)006<1898:LSVOAD>2.0.CO;2

Zhang, T., Perlwitz, J., \& Hoerling, M. P. (2014). What is responsible for the strong observed asymmetry in teleconnections between El Niño and La Niña? Geophysical Research Letters, 41, 1019-1025. https://doi.org/10.1002/2013GL058964

Zhang, W., Wang, Z., Stuecker, M. F., Turner, A. G., Jin, F.-F., \& Geng, X. (2018). Impact of ENSO longitudinal position on teleconnections to the NAO. Climate Dynamics, 15, 257-274. https://doi.org/10.1007/s00382-018-4135-1 